
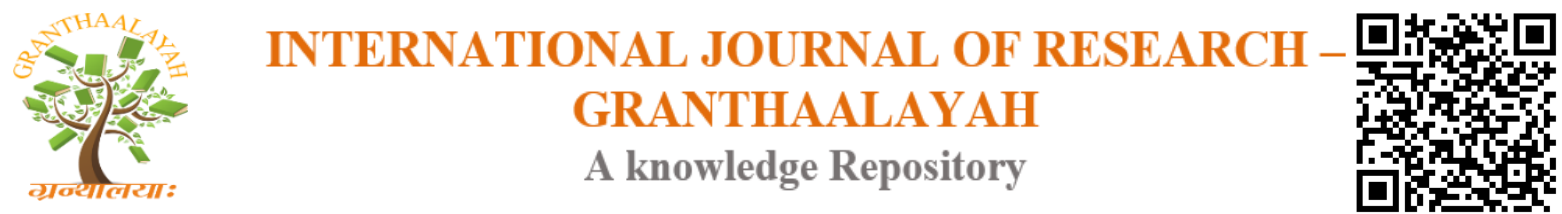

Social

\title{
MINORITY STUDENTS AND INTEGRATIONAL ISSUES IN AN INTERNATIONAL UNIVERSITY IN KURDISTAN
}

\author{
Vijay Kapur *1 \\ ${ }^{* 1}$ Instructor, the American University of Kurdistan, Iraq
}

\begin{abstract}
Over the last few decades, professionals have searched for generalized strategies and techniques to integrate students, but most often these studies have not examined the specific needs of minority students, who are segregated on ground of religion or cultural issues practiced by them, making them different from the majority others. These students often belong to different religious ethnicity and they make up a much smaller percentage and as a result, their experiences and needs at times gets lost and goes undetected. This article intends to investigate the gap between the ideal level of integration and the existing level between diverse groups of students and offers solutions towards bridging the gap in an international university in Kurdistan, northern Iraq.
\end{abstract}

Keywords: Minority; Integrational; Students.

Cite This Article: Vijay Kapur. (2018). "DIGITAL GAMES - MINORITY STUDENTS AND INTEGRATIONAL ISSUES IN AN INTERNATIONAL UNIVERSITY IN KURDISTAN.” International Journal of Research - Granthaalayah, 6(6), 151-160. https://doi.org/10.29121/granthaalayah.v6.i6.2018.1360.

\section{Introduction}

While we all respect difference and diversity somewhere within us the cleavage grows and we start to distinguish between "us" and "them". Although access to education has increased, as most countries advocate mandatory education for all but additional issues have continued to emerge, especially in an university setting. Affirmative and inclusive education is becoming a key word in an educational institution. The means for ensuring diversity are also becoming narrower in a university context so that institutions are devising various strategies to integrate students that are able to enter mainstream society. Over the last few decades, professionals have searched for generalized strategies and techniques to integrate students, but most often these studies have not examined the specific needs of minority students, who are segregated on ground of religion or cultural issues practised by them, making them different from the majority others. These students often belong to different religious ethnicity and they make up a much smaller percentage and as a result, their experiences and needs at times gets lost and goes undetected. Academic campuses do realize that they need to make changes so they are able to integrate minority students. However, few institutions have the strategies to create and make such changes. In this article the researchers 
shall explore the integration of minority students in an international university in Kurdistan, northern Iraq. A complex picture from numerous literature sources will be presented to draw an inference and to provide a foundation based on frameworks advocated by pioneers who have worked in this field. The article begins with an introduction to the current scenario and summarizes the meaning of the term integration, race and ethnicity and its relevance in this context. Qualitative method was used to collect the data and explore the situation as the number of respondents were small and only an in-depth interview could help them reveal their situation.

\section{Research Questions}

This article intends to investigate the gap between the ideal level of integration and the existing level between diverse groups of students and offers solutions towards bridging the gap. Although several studies have been conducted in the past that extol the benefits of being educated in a diverse environment, it is a relatively new area of educational research and, subsequently, can still be strengthened in a number of ways (Denson et al., 2010). Most of the studies concentrate on studying the retention of students and educational attainment and very few concerns themselves with student's experiences and their perceptions regarding integration (Chang, 2005). Some of the earlier studies have focused on outcomes of practicing curriculum diversity which reveal positive intergroup attitudes (Lopez, 2004); racial prejudice and intergroup understanding (Chang, 2005); attitudes toward campus diversity (Springer et al., 1996); critical thinking skills (Laird, 2005; Pascarella et al., 2004); cognitive and affective development (Astin, 1993); and learning and democracy outcomes (Gurin et al., 2002). Two critical questions have been formulated to guide the research:

1) What is the level of integration between ethnicized groups of students in the university and the practical implications faced by the minority religious groups?

2) Are there any institutional and student related practices that support integration?

The research questions have been designed based on two constructs, investigating perception and investigating practice. Students from the minority group were interviewed to find out regarding their own version or comprehension of integration and the various ways they feel the institution should practice integration. Research question 1 deals with perception, the individual's definition of the word, and comprehension of the various policies and measures implemented by the university. Question 2 is practice oriented, this question explores constructive and affirmative action undertaken by the university if any.

\section{Some Common Terminologies}

Scholars in the social sciences soon started abandoning the concept of race as it was solely resting on the laurels of biological and genetic markers and were thus too unspecific and reflecting broad generalizations (Tonkin et al., 1989, Banton, 1998). There has been a lack of clear definition and differentiation to explain the concept of race as a social category (Schwartz, 2001: Cooper 2003). In contrast to race, ethnicity and ethnie seems to be rather a new concept\|, (Glazer and Moynihan, 1975, p.1). This approach takes into account a concept that is more than a genetic or biological factor, although the general meaning of ethnicity is still very fuzzy encompassing the meaning of a group as well as the feeling of belonging to such a group (Tonkin et al., 1989). Scholars have resorted to using an "umbrella classification" (Chandra, 2006, p. 397) which signifies a "shared 
culture, a common ancestry and some form of group membership which are central aspects of defining an ethnic group" (Holst, 2012, p.13). Such a classification has resulted in a "world of separate people, each with their own culture and each organized in a society which can legitimately be isolated for description as an island to itself'"l (Barth, 1969, p.11). Barth argues that the concept of common culture is central to the characteristic of an ethnic group. Hutchison and Smith (1999, p. 4) use the term "ethnicity" while referring to "the other peoples who like animals, belong to some group unlike one's own"ll. The term 'other' becomes a vital component in defining ethnicity: "in their common employment the terms have a strong and familiar bias towards 'difference and otherness" (Tonkin et al., 1998, p.15).

Eriksen (2002, p.6) argues that "boundaries between race and ethnicity tend to be blurred, since ethnic groups have a common myth of origin which relates ethnicity to descent which again makes it a kindred concept to race" $\|$. Smelser et.al (2001, p.4) points out that the "terms race and ethnicity comprise of complex social phenomena that are hardly possible to describe and measure accurately'"l. Fearson and Latin (2002) develop a dual perspective where the construct of ethnic identity has formed due to elite manipulation of the people and at times such constructs can be attributed to discursive formations where the culturist gives emphasis to the logic of a culturally specific way of behaviour.

The term 'integration' in many countries is defined as "assimilation to a pre-existing, unified social order, with a homogeneous culture and set of values. Integration is not only a reciprocal process. It also consists of complex and multi-layered practices: economic, social and cultural. Successful integration cannot be promoted by designating a specific path and outcome"'l (Rudiger et al., 2003, p.4). The term integration lays special emphasis on the concept of unity and stability resulting in social cohesion. Social cohesion does not advocate homogeneity of culture but a pluralist society where members from different cultures foster a bond with the help of continuous social interaction. The concept of integration has a positive connotation: that the society is experiencing stability and the entry of individuals or groups does not endanger or alter the existing system (Baubock, 1995). This article studies the meaning and implementation of the concept of integration in an international university having students of diverse ethnicity.

\section{Kurdistan - the Context}

The Kurdistan Region of Iraq (KRI) has been the home to a myriad of different ethno-religious groups due to a significant level of ethnic and religious tolerance practised by the government who has always promoted an inclusive policy amongst its people. The ethno-religious diversity in the Kurdistan region comprising of the three governorates of Dohuk, Erbil and Sulaimaniyah and parts of the Disputed Territories) is remarkable. Its ethnic components comprise of Kurds, Turkmen, Arabs, Armenians, Chaldean Assyrian and Syriacs, while its religious groups, in addition to Muslims both Sunni and Shia, include Yazidis, Kaka 'is, Christians and smaller groups, such as Zoroastrians, Mandaeans and Baha'is. There are many legal provisions practised by the regional government for the protection of the political and cultural rights of Kurdistan's minorities. However, the years of sectarian conflict that has plagued Iraq have created rifts that are difficult to bridge and often overflows and affects all. 
There is no accurate census data on the total population of different communities in Kurdistan Iraq therefore, numbers and rations of ethnic and religious components remain as estimates (MERI 2015). Following the Kurdistan National Council (Parliament) elections in 1992, the Parliament was formed with one hundred general seats, in addition to five protected seats (quota) for the Christians who were largely members of the Armenian, Chaldean Assyrian and Syriacs communities. "It was not until 2005 when the number of protected seats for minority groups was increased to eleven, five for the Turkmens and five to the Chaldeans, Syriacs, and Assyrian and one for the Armenians. However, no seat was allocated for the Arabs, Yazidis, Kaka'is or other smaller minorities. The KRG Council of Ministries (Cabinets) have so far failed to assign any specialised ministerial positions to the minority representatives" (MERI 2015, p. 7).

\section{The University}

The university under study is not named in this article but certain policies practised by them will be highlighted to showcase the practice paradigm of the study.

The university's mission as stated in its student affairs handbook is to enhance student development and achieve academic success by having facilities, programs and services dedicated to support the student needs in a friendly, confidential and helpful manner every step of the way. The Mission of the department is to:

- Identify and respond to student needs

- Create and foster a safe, healthy, diverse and attractive campus environment

- Respect and empower students by giving them their own voice

- Update knowledge and skills in order to continuously support students at the highest level

- Establish and cultivate a positive and healthy relationship among students, staff, faculty and community

Some of the core values that the university stands for are:

- Integrity - To contribute to a respectful, pleasant, healthy and ethical environment.

- Support - To show genuine concern for health, well-being, balance and academic success.

- Excellence - Commitment to deliver and provide excellent support and advice through continuous improvement of the centre and professional development of the staff.

- Diversity - To embrace, value and appreciate diversity in terms of different ethnicity, religion and ideas.

- Learning - To value gaining and acquiring knowledge and developing necessary life and academic skills needed in order to be successful.

\section{Existing Literature and Theories on Integration}

Researchers studying students' integration in higher educational institutions have come up with various theories and, based on their own studies, have drawn conclusions relating to the problem, although no single method can be accepted as complete or comprehensive enough to account for this complicated issue that influences students (Chang, 2005). Most of the studies concentrate on studying the retention of students and educational attainment and very few concerns themselves with students' experiences and their perceptions regarding integration (Chang, 2005). Antonio et al., (2004) conducted a study using a randomized assignment design which tested psychological 
explanations of the impact of diversity on students. Certain other researchers in this field have focused on curricular and co-curricular diversity that is institutionally structured to help students engage in diversity with respect to both ideas and people (Terenzini et al., 2001).

The relationship between racial diversity and cross-racial interaction, however, is far from clear. Presently "there is a shortage of information about this relationship and the conditions that generally help to maximize cross-racial interaction among undergraduate students", (Chang, 2004, p. 531). The present review of literature has not revealed studies that address students' perceptions regarding 'integration' and how institutions with their policies and practices have dealt with the problem of integration. Most of the work done in this field looks at students' integration from a western perspective and not from a Middle Eastern point of view. There exists a gap in the literature pertaining to the subject of students' integration in a Middle Eastern context. This study aims to address this gap.

\section{Allport's Contact Theory}

Allport's contact theory was framed in the post-world war II era and while using this theory one needs to keep in mind that it was a tumultuous time, when social scientists were seeking avenues to bind the human race in some commonalities amidst hatred and mistrust. This theory still remains one of the most comprehensive frameworks on reducing racial prejudice.

Allport (1954) defined prejudice as "an antipathy based upon a faulty and inflexible generalisation. It may be felt or expressed. It may be directed toward a group as a whole, or toward an individual who is a member of that group"ll, (p.10). The four conditions specified by All port present the guidelines to eliminate the racial bias prevalent amongst out-group members. These four conditions are inherent in an organization and are not difficult to achieve and need not be imported from the outside world and juxtaposed in the structure and culture of the organization and therefore do not demand organizational change.

Allport (1954) suggests that four core conditions are essential when trying to achieve racial integration. These conditions are equal status between the groups in the situation; common goals for the groups; no atmosphere of competition between groups; and the contact situation should be legitimized through institutional support or support of higher authority. Successful integration only occurs when certain conditions in which the intergroup interaction occurs are met. The condition of 'equal group status' occurs when the contributions from a group are equal to those from another group. Allport stresses equal group status within a given situation. Most research supports this contention as it is important that both groups expect and perceive equal status in any given situation (Cohen \& Lotan, 1995; Cohen, 1982; Riordan \& Ruggiero, 1980; Robinson \& Preston, 1976). Researchers have come up with new situational factors for creating optimal contact between groups. Wagner \& Machelit (1986) suggest a few conditions of their own, stating that positive effects require a common language, voluntary contact and a prosperous economy. According to Pettigrew (1998) the original contact hypothesis says nothing about the process by which contact leads to a change in attitude and behaviour. It only predicts that contact will lead to positive change, and not how and why the change occurs. 


\section{Research Methodology: Qualitative Research}

The researcher used qualitative method to derive data from the few minority students who were accessible and were willing to share their experience. Hannafin et al. (1993) explain that qualitative research is defined as research devoted to developing an understanding of human systems. Such research studies typically require considerably more time to design, collect and analyse data and report the results compared to quantitative studies (Savenye et al., 1992). In qualitative studies the design often emerges with the progress of the research with the researcher continually refining the methods and questions. The focus of the study determines the data collected and the boundaries of the study, which evolve as new issues and questions emerge. A qualitative researcher tends to interpret results of a study or draw conclusions based on the particulars that emerge from the study rather than in terms of generalizability to other situations and settings.

Prior to the qualitative interviews a careful planning process was undertaken. Since the qualitative interview is not normally a freewheeling conversation but a planned process, a number of factors have to be taken into account before the onset of the process. It is rare that the interview process can be carried on over a lengthy period of time with limitless opportunities to keep on asking questions. With these constraints in mind there was a need to exercise selectivity in the coverage. Without designing a proper structure for the interview the participants might find the large range of questions asked quite perplexing and possibly intrusive (Sengupta, 2015). It was necessary to explain the purpose of the interview in a simple manner so as to meet the objectives of the research. A skeletal outline of the interview, beginning with the design of the questions that needed to be asked, was prepared. These questions would serve as an 'interview guide' and included the areas or topics that had to be covered through the interview. These semi-structured questions would be a guide, keeping in mind that an unanticipated issue might emerge in the interview and sufficient supplementary questions might have to be introduced at that moment to fully explore the issue from the participant's perspective. At the very onset it was realized that the role of the researcher would be more that of an 'active listener' absorbing as much of what was being said and formulating further questions to fill in the gaps where the account was unclear, short or contradictory in nature. The interview questions were formulated in a 'natural, sensible and helpful sequence' (Howitt, 2010).

\section{The Participants}

Approaching the participants did not result in an overwhelming response. Participants from the religious minority groups were sceptical and rather scared lest their response would be used against them and perhaps reflect in their evaluation. A suitable quiet place available during the day for the interviews was selected, a place where there would be no interruptions, was sought for and students were called in separate religious groups. The researcher did not record the interviews as students displayed their discomfort in being recorded hence hand-written notes were taken during the process of the interview. The researcher's main spoken contribution was at the beginning of the interview at the introductory stage. This phase consisted of introducing the researcher, explaining the purpose of the interview and asking the interviewees to introduce themselves. The interview was punctuated with questions which served as cues for the participants to share their in-depth perceptions and experiences. The researcher tried to understand and build a mental picture of what the interviewee was trying to say. There was more focus on engaging with the replies of the 
interviewee to determine if there was a need to extend the question, insert probes or seek clarification from the participant. The objective was to ensure that the details in the answers were sufficient from the perspective of data collection and were adequate for the research.

There were three groups consisting of Yezidis, Arabs and Assyrian Christians. There were 6 participants from the Yezidi groups, 3 from the Arabs and 2 from the Assyrians. No data was available from the registration department as to how many minority students were there in total number amongst a cohort of 500 students. The Yezidi students were very forthcoming and shared their experience. These students are all enrolled in undergraduate programme in various streams like business management, fine arts, engineering and political science. Only 1 Yezidi student was still undergoing his course in English proficiency before he can enrol in any undergraduate programme. The interviews were conducted in groups and resulted in a focus group discussion. In the group only 1 or 2 student took the lead and shared their experience while others were reticent and restrained from opening up to the conversation.

\section{Findings and Analysis of Data}

Once the compilation of the data was completed, the coding process was started, using NVivo software, at times line by line and sometimes taking two or three lines together. Codes are small chunks of data which are a level of abstraction away from the data. It is from these codes that, at a later stage, the themes to describe the major features of the data were developed. The analysis began with detailed coding and conceptualization either through line by line coding or at times applying a 'broad brush' approach.

\section{Themes}

The very first theme that was generated from the qualitative interviews was 'segregation'. "We are never like them, they even refuse to touch the food that we bring as it is not halal, they think that our food is dirty" (Participant A).

"They never invite us to their party's or celebrations. Sometimes they do come and be a part of ours, they eat and then they go away without even thanking us once, it seems that next day they don't even know us. They ignore our wave, or nod", (Participant C).

Almost $90 \%$ of the participants felt that the rest of the students refuse to include them in their ingroups hence they try to form their own group and at times these groups are all minority students together irrespective of their religion. The feel a kind of bonding as they are all from the 'unwanted' few.

The next theme that came up while decoding the interviews was "under representation". "We try to participate in the social functions but we are not allowed to be the part of the main group organizing the event, sometimes we are merely treated as hang arounds and sometimes we face downright refusal, with no explanation." (Participant C) 
"We don't get to stand for election or become an office bearer, then they cite that your GPA is not up to the mark, no no ....never... there are no seats reserved to represent the minority students in the senate". (Participant B)

The third theme that was derived from the interviews was 'invisibility'. Most of the students belonging to the minority groups preferred to remain invisible and not to highlight their identity especially with the majority group. They knew that talking about their religious belief or even their origin (like the Arabs) may result in trouble.

"We are afraid, we don't talk...sometimes their write hate words in the dust of our cars, or maybe a scratch mark on our car, we just keep quiet, who will listen to our complaints and even if they do we will have to face these same students later..." (Participant D).

"Some faculty members doesn't like us because we cannot speak in Kurdish, or don't know Kurdish literature, they have failed us more than 5 times... how is it possible that we cannot pass even after attending the class 5 times and giving the exams... we don't know what to do, we prefer not attending his class.." (Participant A)

\section{Recommendations}

Integration between the majority and minority students cannot be implemented by any individual alone; any change needs the approval of the masses and there should be a consensus in making decisions. One of the most important tasks in crafting a strategy towards optimal integration in a university is the management of the interface between the various stakeholders in the university. To decide upon a strategy the university needs to engage with its stakeholders who may be found in groups or individuals whose actions and interest in the university have an impact on its environment and have a direct bearing on the outcomes of the strategy that aims at total integration. The university needs to anticipate and manage these outcomes in order to create goodwill towards the university and enhance its reputation. Once the stakeholders have been identified, the university committee in charge of the integration programme should prioritize the stakeholders on the basis of the task in hand. All stakeholders need not be consulted at all stages and based on the task some stakeholders may occupy a more important position compared to the others.

Conflict resolution is a skill that should be taught in the university in order to improve intergroup relations (Deutsch, 1993). Learning to resolve conflicts between people of different ethnicity also involves understanding their origins, differences in values, beliefs, and norms. Students should also learn how to avoid conflict by using techniques of de-escalation such as negotiation, bargaining, making concessions, apologising or explaining (Fisher, 1994). These skills will help students when they graduate and join the larger community of working professionals. Such skills acquired in the university will help reduce uncertainty and anxiety concerning interaction with outgroup members.

Faculty should practice the use of assessment based on a range of formative and summative assessment strategies that give students from every diverse group an opportunity to demonstrate mastery. These strategies should include observation, oral examinations, performance, and teacher-made as well as standardized measures and assessments. Faculty must possess the 
intellectual, affective and action skills required to adequately prepare students for a multicultural future. Students must be able to know, think, feel, believe, and behave in ways that demonstrate respect for people, experiences, issues, and perspectives that are different from their own (Banks, 2001).

Allport (1954), in his social contact theory, specifies a common goal and cooperation as one of the factors needed to reduce bias between groups. A common goal is defined as one that can only be attained if all the members of different groups work together through inter-group cooperation and not through competition (Cross \& Rosenthal, 1999). When members of a group interact they are given the opportunity to work together, to communicate, to express values, to argue, to compromise, to reach agreement, and to gain information about their own group members and of their out-group members (Gaertner et al., 1999).

\section{Scope of Further Research and Conclusion}

Future research in this area could be conducted with other international universities and comparisons can be drawn with public universities enrolling minority students in various faculties. The planning, administering and outcome of any recommendation as suggested in this study could be investigated for its impact. In this university intervention of service learning with the local community, encouraging students to participate in multi-cultural exchange programmes, introducing elements of multi-culturalism in the curriculum or cultural induction could be introduced at various stages to measure and monitor the outcomes of such interventions. The problem needs to be identified and adequate attention should be given to solve the issue before it snowballs into a much bigger problem resulting in drop-outs, depression and other deviant behaviour in the students.

\section{References}

[1] Allport, G. W. (1954). The nature of prejudice. Reading, MA: Addison-Wesley

[2] Banks, J. A. (2001). Cultural diversity and education: Foundations, curriculum and teaching (4th ed.). Boston: Allyn and Bacon

[3] Barth, F. (1969). Introduction in Barth F. (ed.) Ethnic groups and boundaries: The social organization of cultural differences, London: Allen and Unwin, Cooper, R.S. (2003). Race, genes and health: New wine in old bottles? International Journal of Epidemiology, 32(1); 23-25.

[4] Baubock, R. (1995). The integration of immigrant. Vienna, Austria: Institut fur Hohere Studien/ Institute for Advanced Studies in Vienna.

[5] Chandra, K. (2006). What is ethnic identity and does it matter? Annual Review of Political Science, 9. 397-424.

[6] Chang, M. J. (2005). Reconsidering the diversity rationale. Liberal Education, 2005, 91(1), 6-13.

[7] Cohen, A.P. (1982) Belonging: Identity and Social Organisation in British Rural Cultures Issue 1 of Anthropological studies of Britain. Manchester University Press

[8] Cohen, E. G., \& Lotan, R. A. (1995). Producing equal-status interaction in the heterogeneous classroom. American Educational Research Journal, 32(1), 99-120.

[9] Cross, S. and Rosenthal, R (1999). Three models of conflict resolution: Effects on intergroup expectancies and attitudes. Journal of Social Issues . Volume 55, Issue 3, pages 561-580. Fall 1999.

[10] Deutsch, M. (1993). Cooperative learning and conflict resolution in an alternative high school. Cooperative Learning, 13, $2-5$.

[11] Eriksen, T.H. (2002). Ethnicity and nationalism. London. Pluto Press. 
[12] Fisher, R. (1994). General principles for resolving intergroup conflict. Journal of Social Issues, 50, 47-66.

[13] Gaertner, S. L., Sedikides, C., and Graetz, K. (1999). In search of self-definition: Motivational primacy of the individual self, motivational primacy of the collective self, or contextual primacy? Journal of Personality and Social Psychology, 76, 5-18

[14] Glazer, N. and Moynihan, D.P. (1975). Introduction, in Glazer, N. and Moynihan, D.P. (eds.) Ethnicity: Theory and experience, Cambridge, MA: Harvard University Press.

[15] Hannafin, R., and Savenye, W. (1993). Technology in the classroom: The teacher's new role and resistance to it. Educational Technology, 33(6), 26-31.

[16] Holst, F. (2012). Ethnicization and identity construction in Malaysia. Routledge Malaysian Studies Series.

[17] Howitt, D. (2010). Introduction to qualitative methods in psychology. Loughborough University.

[18] Hutchinson, J. and Smith, A.D. (1996). Introduction, in Hutchinson, J. and Smith, A.D. (eds.) Ethnicity, Oxford: Oxford University Press.

[19] Pascarella, E. T., Pierson, C. T., Wolniak, G. C., and Terenzini, P. T. (2004). First generation college students: Additional evidence on college experiences and outcomes. The Journal of Higher Education, 75(3), 249-284.

[20] Pettigrew, T.F. (1998). Intergroup contact theory. Annu Rev Psychol. 1998; 49:65-85. DOI: 10.1146/annurev.psych.49.1.65

[21] Riordan, C., \& Ruggiero, J. (1980). Producing equal-status interracial interaction: A replication. Social Psychology Quarterly, 43(1), 131-136.

[22] Robinson, J. and Preston, J. (1976). Equal-Status Contact and Modification of Racial Prejudice: A Re-examination of the Contact Hypothesis. Social Forces, 54(4), p.911.

[23] Rudiger, A. and Spencer, S. (2003). Social integration of migrants and ethnic minorities. Policies to combat discrimination. OECD, Brussels. 2003.

[24] Savenye, W. C., Davidson, G. V. and Orr, K. B. (1992). Effects of an educational computing course on pre-service teachers' attitudes toward computers. Journal of Computing in Childhood Education, $3,31-41$.

\footnotetext{
*Corresponding author.

E-mail address: kapurvij@ gmail.com
} 